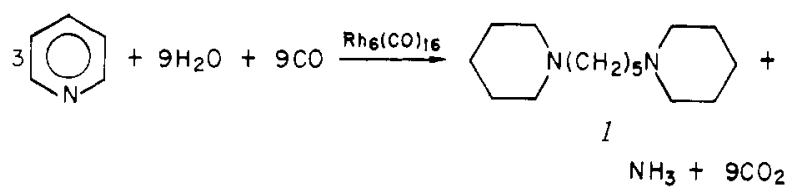

Finally, HDN C-N cleavage normally results in the formation of $\mathrm{N}-\mathrm{H}$ and $\mathrm{C}-\mathrm{H}$ bonds. ${ }^{4}$ Analysis of the gas phase above the CoMo reactions in which $\mathrm{Et}_{2} \mathrm{NH}$ was observed revealed only hydrogen. The ethyl groups lost are observed by GC-mass spectroscopy as $\mathrm{Et}_{2} \mathrm{NBu}$ and $\mathrm{EtOH}$. The mechanism of transformation of two ethyl groups to a butyl group or one ethyl group to ethanol is not apparent; however, in the rhodium and osmium modeling studies of $\mathrm{CoMo}, \mathrm{Et}_{3} \mathrm{~N}$ is also observed to lose ethyl groups to obtain $\mathrm{Et}_{2} \mathrm{NH}$ and coincidently to produce $\mathrm{Et}_{2} \mathrm{NBu}$ and EtOH. This represents an additional reaction parameter that supports reliable modeling of the reactivity patterns of the heterogeneous HDN catalyst, CoMo, using a homogeneous catalyst derived from $\mathrm{Rh}_{6}(\mathrm{CO})_{16}$.

Sufficient information is now available from the catalytic and stoichiometric reactions of amines with organometallic compounds to propose and test a complete mechanistic scheme for $\mathrm{C}-\mathrm{N}$ bond cleavage in the HDN process. ${ }^{12}$

Acknowledgment. We thank the National Science Foundation for their generous support of this work through CHE Grant No. 78-25069. RML would also like to thank Professor Michel Blanchard and the Universite de Poitiers for a sabbatical leave position.

Registry No. $\mathrm{Rh}_{6}(\mathrm{CO})_{16}, 28407-51-4 ; \mathrm{Ru}_{3}(\mathrm{CO})_{12}, 15243-33-1 ; \mathrm{Os}_{3}$ (CO) ${ }_{12}, 15696-40-9 ; \mathrm{Et}_{3} \mathrm{~N}, 121-44-8 ; \mathrm{Pr}_{3} \mathrm{~N}, 102-69-2 ; \mathrm{Bu}_{3} \mathrm{~N}, 102-82-9$

(12) Laine, R. M., to be submitted for publication.

\section{Synthesis and Crystal Structure of $\left(\eta^{5}-\mathrm{C}_{5} \mathrm{Me}_{5}\right)_{2} \mathrm{Cr}_{2} \mathrm{~S}_{5}$ Containing an Unusual $\eta^{1}$-( $\mu$-Disulfide) Ligand}

Henri Brunner and Joachim Wachter*

Institut für Anorganische Chemie, Universität Regensburg D-8400 Regensburg, West Germany

Ernst Guggolz and Manfred L. Ziegler

Anorganisch-chemisches Institut, Universität Heidelberg D-6900 Heidelberg 1, West Germany

Received November 5, 1981

Among transition-metal complexes with a metal-metal triple bond, $\left[\left(\eta^{5}-\mathrm{C}_{5} \mathrm{H}_{5}\right)(\mathrm{CO})_{2} \mathrm{Mo}\right]_{2}$ plays a unique role because of its versatile reaction possibilities. ${ }^{1}$ In contrast, little is known concerning the reactivity of its chromium analogue, for which only the reactions with small nucleophiles, e.g., $\mathrm{CO}^{2}$ and $\mathrm{RC} \equiv \mathrm{CR},{ }^{3}$ have been observed to give well-defined products. We chose $\left[\left(\eta^{5}-\mathrm{C}_{5} \mathrm{Me}_{5}\right)(\mathrm{CO})_{2} \mathrm{Cr}\right]_{2}{ }^{2}$ as starting material for the reaction with elemental sulfur, because we expected the five methyl substituents at the cyclopentadienyl ligand to favor the reaction. ${ }^{4}$

The reaction of $\left[\left(\eta^{5}-\mathrm{C}_{5} \mathrm{Me}_{5}\right)(\mathrm{CO})_{2} \mathrm{Cr}\right]_{2}$ with an excess of sulfur in toluene $e^{5}$ gives as the only isolable product black-green crystals

(1) See for example: Curtis, M. D.; Klingler, R. J. J. Organomet. Chem. 1978, 161, 23. Wachter, J.; Mitschler, A.; Riess, J. G. J. Am. Chem. Soc. 1981, 103,2121 and references cited therein.

(2) King, R. B.; Iqbal, M. Z.; King, A. D., Jr. J. Organomet. Chem. 1979, 171,53 .

(3) Knox, S. A. R.; Stansfield, R. F. D.; Stone, F. G. A.; Winter, M. J.; Woodward, P. J. Chem. Soc., Chem. Commun. 1978, 221. Bradley, J.S. J. Organomet. Chem 1978, 150, C1.

(4) Rakowski DuBois, M.; DuBois, D. L.; VanDerveer, M. C.; Haltiwanger, R. C. Inorg. Chem. 1981, 20, 3064.
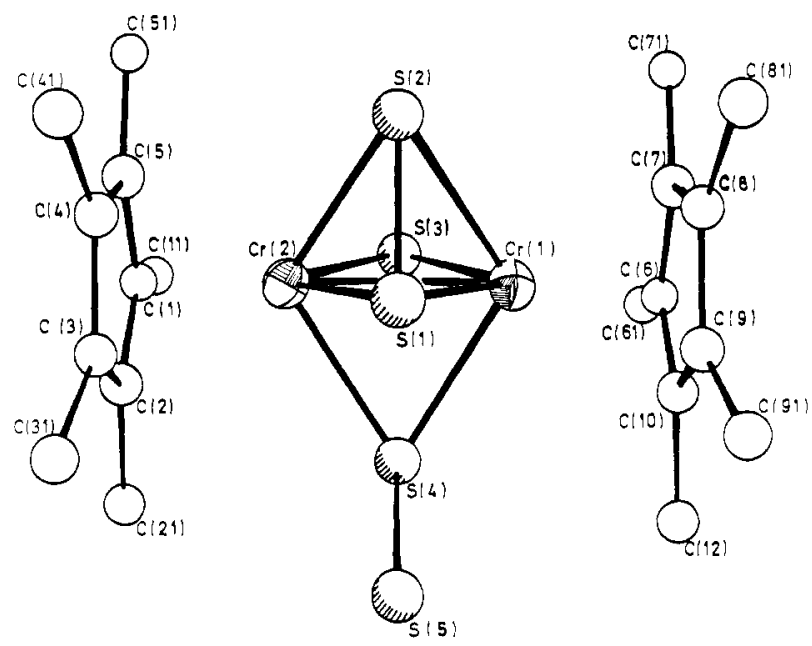

Figure 1. View of $\left(\eta^{5}-\mathrm{C}_{5} \mathrm{Me}_{5}\right)_{2} \mathrm{Cr}_{2} \mathrm{~S}_{5}$.

Table I. Selected Bond Lengths $d(\hat{A})$ and Bond Angles $\omega$ (Deg)

\begin{tabular}{|c|c|c|c|}
\hline bond & $d$ & angle & $\omega$ \\
\hline $\operatorname{Cr}(1)-\operatorname{Cr}(2)$ & $2.489(2)$ & $\operatorname{Cr}(1)-\mathrm{S}(1)-\operatorname{Cr}(2)$ & $65.6(1)$ \\
\hline $\mathrm{Cr}(1)-\mathrm{S}(1)$ & $2.295(4)$ & $\mathrm{Cr}(1)-\mathrm{S}(1)-\mathrm{S}(2)$ & $62.1(1)$ \\
\hline $\mathrm{Cr}(1)-\mathrm{S}(2)$ & $2.297(3)$ & $\mathrm{Cr}(1)-\mathrm{S}(2)-\operatorname{Cr}(2)$ & $65.7(1)$ \\
\hline $\mathrm{Cr}(1)-\mathrm{S}(3)$ & $2.239(3)$ & $\mathrm{Cr}(1)-\mathrm{S}(2)-\mathrm{S}(1)$ & $62.1(1)$ \\
\hline $\operatorname{Cr}(1)-S(4)$ & $2.344(4)$ & $\operatorname{Cr}(1)-\mathrm{S}(3)-\mathrm{Cr}(2)$ & $67.6(1)$ \\
\hline $\mathrm{Cr}(1)-\mathrm{C}\left(\mathrm{C}_{5} \mathrm{Me}_{5}\right)$ & $2.233(9)$ & $\operatorname{Cr}(1)-\mathrm{S}(4)-\operatorname{Cr}(2)$ & $64.0(1)$ \\
\hline $\operatorname{Cr}(2)-S(1)$ & $2.302(4)$ & $\mathrm{Cr}(1)-\mathrm{S}(4)-\mathrm{S}(5)$ & $108.8(1)$ \\
\hline $\mathrm{Cr}(2)-\mathrm{S}(2)$ & $2.292(3)$ & $\mathrm{Cr}(2)-\mathrm{S}(1)-\mathrm{S}(2)$ & $61.9(1)$ \\
\hline $\operatorname{Cr}(2)-S(3)$ & $2.238(3)$ & $\mathrm{Cr}(2)-\mathrm{S}(2)-\mathrm{S}(1)$ & $62.3(1)$ \\
\hline $\operatorname{Cr}(2)-\mathrm{S}(4)$ & $2.354(4)$ & $\operatorname{Cr}(2)-\mathrm{S}(4)-\mathrm{S}(5)$ & $108.8(2)$ \\
\hline $\mathrm{Cr}(2)-\mathrm{C}\left(\mathrm{C}_{5} \mathrm{Me}_{5}\right)$ & $2.227(9)$ & $S(1)-C r(1)-S(2)$ & $55.8(1)$ \\
\hline$S(1)-S(2)$ & $2.149(5)$ & $S(1)-C r(1)-S(4)$ & $76.1(1)$ \\
\hline \multirow[t]{2}{*}{$S(4)-S(5)$} & $2.101(5)$ & $S(2)-C r(1)-S(3)$ & $84.0(1)$ \\
\hline & & $S(3)-C r(1)-S(4)$ & 74.1 (1) \\
\hline
\end{tabular}

of the diamagnetic complex $\left(\mathrm{C}_{5} \mathrm{Me}_{5}\right)_{2} \mathrm{Cr}_{2} \mathrm{~S}_{5}$. The compound has been characterized by total elemental analysis. The $70-\mathrm{eV}$ mass spectrum consists of the parent ion followed by consecutive loss of three sulfur atoms, giving the most stable fragment $\left(\mathrm{C}_{5} \mathrm{Me}_{5}\right)_{2} \mathrm{Cr}_{2} \mathrm{~S}_{2}{ }^{+}$. The ${ }^{1} \mathrm{H}$ NMR spectrum exhibits only one singlet at $2.13 \mathrm{ppm}\left(\mathrm{CDCl}_{3}\right)$, which indicates a symmetric structure with respect to the $\mathrm{C}_{5} \mathrm{Me}_{5}$ groups. Infrared absorptions ( $\mathrm{KBr}$ disk) at $598 \mathrm{w}, 495 \mathrm{~m}$, and $445 \mathrm{w} \mathrm{cm}^{-1}$ may be attributed to different $\mathrm{Cr}-\mathrm{S}$ bonding modes. As these spectroscopic data were not sufficient for a structural characterization of the new complex, an X-ray crystal structure was carried out. The monoclinic crystals crystallize in the space group $C_{2 h}^{5}-P 2_{1} / c$, with cell constants $a=$ $13.970(5) \AA, b=10.188(3) \AA, c=16.482(5) \AA ; \beta=92.46(3)^{\circ}$; $V=2343.6 \AA^{3} ; Z=4$. Of 3210 measured reflections (Mo K $\alpha$ radiation), 2212 with $I \geq 2.5 \sigma(I)$ were used for the refinement of the structure $\left(R_{F}=0.062\right)$.

The dominating feature of the structure (Figure 1) is the plane of the five sulfur atoms, perpendicular to the metal-metal bond and parallel to the two $\eta^{5}-\mathrm{C}_{5} \mathrm{Me}_{5}$ planes. It contains three different types of sulfur ligands: (i) a $\mu-\mathrm{S}$ ligand, $\mathrm{S}(3)$, bridging the two $\mathrm{Cr}$ atoms in the usual way; ${ }^{6}$ (ii) a $\eta^{2}(\mu-\mathrm{S}, \mu-\mathrm{S})$ ligand, $\mathbf{S}(1) \mathrm{S}(2)$, forming a side-on bonded disulfur bridge, ${ }^{7}$ (iii) a $\eta^{1}(\mu-\mathrm{S}, \mathrm{S})$ ligand, representing a novel type of disulfur bridge in which $S(4)$ is coordinated to both $\mathrm{Cr}$ atoms, leaving $\mathrm{S}(5)$ uncoordinated. Whereas the atoms $S(1)-S(4)$ are in a nearly square-planar arrangement around the $\mathrm{Cr}-\mathrm{Cr}$ axis, the bond $\mathrm{S}(4)-\mathrm{S}(5)$ is bent with respect to the plane $\mathrm{Cr}(1)-\mathrm{S}(4)-\mathrm{Cr}(2)$ with $\mathrm{S}(5)$ oriented

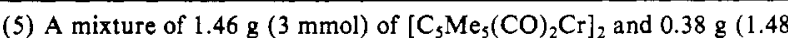
mmol) of $\mathrm{S}_{8}$ in $100 \mathrm{~mL}$ of toluene was stirred at $45^{\circ} \mathrm{C}$ for $17 \mathrm{~h}$. The reaction mixture was filtered, concentrated, and chromatographed $\left(30 \times 3 \mathrm{~cm}, \mathrm{SiO}_{2}\right)$ Unreacted starting material was eluted with toluene as a green band, followed by a dark green band of $\left(\mathrm{C}_{5} \mathrm{Me}_{5}\right)_{2} \mathrm{Cr}_{2} \mathrm{~S}_{5}$ ( $22 \%$ yield), eluted with $3: 1$ toluene:ether. Black-green prisms were obtained by recrystallization from toluene at $-35^{\circ} \mathrm{C}$.

(6) Vahrenkamp, H. Angew. Chem., Int. Ed. Engl. 1975, 14, 322

(7) Müller, A.; Jaegermann, W. Inorg. Chem. 1979, 18, 2631 
toward S(1) (intramolecular distance $2.91 \AA$ ). Although the bond length $S(4)-S(5)(2.101 \AA)$ is somewhat shorter than that of $\mathrm{S}(1)-\mathrm{S}(2)(2.149 \AA)$ (Table I), both values are about $0.1 \AA$ longer than expected for disulfur ligands, ${ }^{7}$ in agreement with the low. frequency IR bands at 495 and $445 \mathrm{~cm}^{-1}$, although another IR absorption is observed at $598 \mathrm{~cm}^{-1}$.

Considering the new ligand $\eta^{1}(\mu-\mathrm{S}, \mathrm{S})$ as a two-electron donor similar to the ligand $\mu-\mathrm{S}$ and the ligand $\eta^{2}(\mu-\mathrm{S}, \mu-\mathrm{S})$ as a sixelectron donor, the $\mathrm{Cr}$ atoms achieve noble gas configuration provided a metal-metal double bond is assumed. Alternatively, taking the $\mathrm{C}_{5} \mathrm{Me}_{5}$ ligands as monoanions and the three different sulfur ligands as dianions, each of the $\mathrm{Cr}$ atoms is left in a $\mathrm{d}^{2}$ configuration and a $\mathrm{Cr}-\mathrm{Cr}$ double bond is required to explain the diamagnetism of the complex. In agreement with these considerations a $\mathrm{Cr}-\mathrm{Cr}$ distance of $2.489 \AA$ is found, which is slightly longer than in the starting material $(2.28 \AA){ }^{8}$

At the moment it is not clear why the coordination of a $\eta^{1}(\mu-$ $\mathrm{S}, \mathrm{S})$ disulfur ligand is preferred to a simple $\mu$-S ligand, which is electronically equivalent. In any case no compound of the composition $\left(\mathrm{C}_{5} \mathrm{Me}_{5}\right)_{2} \mathrm{Cr}_{2} \mathrm{~S}_{4}$ has been observed in the reaction of $\left[\left(\mathrm{C}_{5} \mathrm{Me}_{5}\right)_{2}(\mathrm{CO})_{2} \mathrm{Cr}\right]_{2}$ with sulfur, but it is formed by sulfur abstraction from $\left(\mathrm{C}_{5} \mathrm{Me}_{5}\right)_{2} \mathrm{Cr}_{2} \mathrm{~S}_{5}$ with $\mathrm{P}\left(\mathrm{C}_{6} \mathrm{H}_{5}\right)_{3} \cdot{ }^{9}$ However, extended studies on the reaction of $\left(\mathrm{C}_{5} \mathrm{Me}_{5}\right)_{2} \mathrm{M}_{2}(\mathrm{CO})_{4}(\mathrm{M}=\mathrm{Mo}$, W) with $S_{8}$ show that in the molybdenum and tungsten series under the same conditions several isomers of composition $\left(\mathrm{C}_{5} \mathrm{Me}_{5}\right)_{2} \mathrm{M}_{2} \mathrm{~S}_{4}$ can be obtained. ${ }^{10}$

Acknowledgment. We thank the Deutsche Forschungsgemeinschaft, the Fonds der Chemischen Industrie, and the BASF AG for support of this work.

Registry No. $\left(\mathrm{C}_{5} \mathrm{Me}_{5}\right)_{2} \mathrm{Cr}_{2} \mathrm{~S}_{5}, 80765-35-1 ;\left[\left(\eta^{5}-\mathrm{C}_{5} \mathrm{Me}_{5}\right)(\mathrm{CO})_{2} \mathrm{Cr}\right]_{2}$, 37299-12-0; $\mathrm{S}_{8}, 10544-50-0$.

Supplementary Material Available: A listing of atomic positions and thermal parameters ( 2 pages). Ordering information is given on any current masthead page.

(8) Potenza, J.; Giordano, P.; Mastropaolo, D.; Efraty, A. Inorg. Chem. $1974,13,2450$

(9) Unpublished results.

(10) Brunner, H.; Guggolz, E.; Meier, W.; Wachter, J.; Ziegler, M. L., to be submitted for publication.

\section{Effect of Reagent Rotation on Cross Section for the Reaction $\mathrm{Li}+\mathrm{FH} \rightarrow \mathrm{LiF}+\mathrm{H}$}

I. NoorBatcha ${ }^{1 \mathrm{a}, \mathrm{b}}$ and N. Sathyamurthy*1c,d

Department of Chemistry Indian Institute of Technology Kanpur 208016, India

Received September 9, 1981

In this communication, we report on the effect of reagent rotation on the cross section for the reaction

$$
\mathrm{Li}+\mathrm{FH} \rightarrow \mathrm{LiF}+\mathrm{H}
$$

for $\mathrm{HF}$ in its $v=2$ vibrational state in the range of rotational state $0 \leq J \leq 9$, at a relative translational energy of $T=8.7 \mathrm{kcal} \mathrm{mol}^{-1}$, based on three-dimensional quasi-classical trajectory ${ }^{2}$ (QCT) studies on an ab initio potential-energy surface (PES). ${ }^{3,4}$ The

(1) (a) In partial fulfillment of the requirements for the degree of Doctor of Philosophy. (b) On leave from the American College, Madurai 625010 India, under the FIP scheme. (c) This research was supported in part by a grant from the Department of Science and Technology, India. (d) The calculations reported in this paper were carried out on a DEC-1090 computer at the Indian Institute of Technology, Kanpur.

(2) Porter, R. N.; Raff, L. M. In "Dynamics of Molecular Collisions"; part

B; Miller, W. H., Ed.; Plenum Press: New York, 1976; Chapter 1.

(3) Chen, M. M. L.; Schaefer, H. F., III J. Chem. Phys, 1980, 72, 4376.

(4) Carter, S.; Murrell, J. N. Mol. Phys. 1980, 41, 567. reaction cross section $\left(S_{\mathrm{f}}\right)$ decreases initially and then increases with an increase in $J$. The former effect is attributed to the disruption of the favored orientation for the reaction. The latter effect is explained on the basis of the $\mathrm{F}-\mathrm{H}$ bond stretching due to centrifugal distortion at large $(J, v)$. Under the conditions employed in this study, at large $J$, reagent rotation is nearly 4 times more efficient than reagent vibration, which in turn is more effective than reagent translation in causing the reaction.

Although the last 20 years have witnessed an increase in understanding of the effect of reagent translation and vibration ${ }^{5}$ on the rates of chemical reactions, the study of the effect of reagent rotation has been limited, and as a result, the understanding of the role of reagent rotation in chemical reactions has remained poor.

The QCT studies ${ }^{6}$ of the effect of $J$ on $S_{\mathrm{r}}$ have mostly focused their attention on the reaction

$$
\mathrm{F}+\mathrm{H}_{2} \rightarrow \mathrm{FH}+\mathrm{H}
$$

and its isotopic analogues. Depending on the PES employed, the effect of increasing $J$ on $S_{\mathrm{r}}$ was varied: (1) a dramatic drop in $S_{t}$ followed by a leveling off of the same; (2) a slight increase in $S_{\mathrm{r}}$ from $J=0$ to 1 followed by a decrease in $S_{\mathrm{r}}$; (3) a substantial initial decrease followed by an increase in $S_{\mathrm{r}}$. Experimentally, Klein and Persky ${ }^{7}$ showed that the rate of reaction 2 was nearly insensitive to $J$ in the range $J=0-2$. Bernstein ${ }^{8}$ and co-workers showed that a small increase in the reagent rotational energy $(R)$ resulted in a small increase in the reactivity for the reaction

$$
\mathrm{K}+\mathrm{FCs} \rightarrow[\mathrm{KFCs}] \rightarrow \mathrm{KF}+\mathrm{Cs}
$$

and a small decrease for the reaction

$$
\mathrm{K}+\mathrm{FRb} \rightarrow[\mathrm{KFRb}] \rightarrow \mathrm{KF}+\mathrm{Rb}
$$

In both cases, the effect of reagent rotation on $S_{\mathrm{r}}$ was analogous to that of relative translation.

In recent years, there have been some experimental results available for some alkali atom-hydrogen halide reactions. Blackwell et al. ${ }^{9}$ concluded from chemiluminescence depletion experiments on the reactions

$$
\mathrm{Na}+\mathrm{XH}(\mathrm{X}=\mathrm{F}, \mathrm{Cl}) \rightarrow \mathrm{NaX}+\mathrm{H}
$$

that there was an initial decrease followed by an increase in the reaction rate with increase in $J$. The initial decline was also observed by Dispert et al. ${ }^{10}$ for the related reaction

$$
\mathrm{K}+\mathrm{ClH} \rightarrow \mathrm{KCl}+\mathrm{H}
$$

None of these reactions has been studied so far theoretically to understand why there is a decreasing/increasing effect of $J$ on the reaction rate. Recently, however, for the simplest alkali atom-hydrogen halide reaction (1), a fairly accurate $a b$ initio PES has become available $e^{3,11}$ and has also been fitted to an analytic function. ${ }^{4}$ Therefore we found this to be an ideal system for which the effect of reagent rotation on reaction cross section could be studied theoretically.

We have carried out QCT calculations for this reaction on an $a b$ initio surface. We have chosen $v=2$ since the chemiluminescence depletion experiments ${ }^{9}$ on $\mathrm{Na}+\mathrm{FH}$ had $v$ in the range 1-6. The value of $T=8.7 \mathrm{kcal} \mathrm{mol}^{-1}$ employed in this study is the same as that employed in the only molecular-beam study ${ }^{12}$ of this reaction (1). The details of the QCT method are described elsewhere. ${ }^{2}$ We mention only that the impact parameter was sampled in a stratified manner and other variables of orientation angles and vibrational phase were selected randomly.

(5) Kneba, M.; Wolfrum, J. Annu. Rev. Phys. Chem. 1980, 31, 47.

(6) Polanyi, J. C.; Schreiber, J. L. Faraday Discuss. Chem. Soc. 1977, 62 , 267 and references therein.

(7) Klein, F. S.; Persky, A. J. Chem. Phys. 1974, 61, 2472.

(8) Stolte, S.; Proctor, A. E.; Pope, W. M.; Bernstein, R. B. J. Chem. Phys. 1977, 64, 3468. Zandee, L.; Bernstein, R. B. J. Chem. Phys. 1978, 68, 3760.

(9) Blackwell, B. A.; Polanyi, J. C.; Sloan, J. J. Chem. Phys. 1978, 30, 299.

(10) Dispert, H. H.; Geis, M. W.; Brooks, P. R. J. Chem. Phys. 1979, 70 , 5317.

(11) Balint-Kurti, G. G.; Yardley, R. N. Faraday Discuss. Chem. Soc. 1977, 62,77

(12) Becker, C. H.; Casavecchia, P.; Tiedemann, P. W.; Valentini, J. J.: Lee, Y. T. J. Chem. Phys. 1980, 73, 2833. 